\title{
Dysautonomia in a Bitch with Hypothyroidism
}

\author{
Paula Priscila Correia Costa ${ }^{1,2}$, Danilo Galvão Rocha', Juliana Dias ${ }^{3}$, Thaís Aparecida Kazimoto³, \\ Leonardo Alves Rodrigues Cabral ${ }^{3}$, Maressa Holanda dos Santos ${ }^{3}$, Windleyanne Gonçalves \\ Amorim Bezerra ${ }^{3}$, Greyce Luri Sasahara' ${ }^{1}$ Thais Muratori Holanda'
}

\begin{abstract}
Background: Thyroid hormones have important effects on the cardiovascular system, of which the main ones are the increase in the heart response to the autonomic sympathetic nervous system. Heart rate variability is a non-invasive method of assessing autonomic heart modulation, thus being an important form of evaluation in patients with thyroid dysfunctions. This study aimed to report electrocardiographic and heart rate variability data of a dog with hypothyroidism that presented a parasympathetic dysfunction.

Case: A 7-year-old female Dalmatian dog was admitted for clinical evaluation in Fortaleza, Brazil. According to the owner, she had been apathetic for a year, had gained weight, always had a sad expression, and her hair was generally brittle and opaque. On physical examination, skin lesions were observed at the end of the spine, extending to the tail region, with the latter showing total alopecia. Low T4 levels confirmed the diagnosis of primary hypothyroidism. Then, a 24-h Holter monitoring was performed, which showed that the animal had sinus arrhythmia associated with moments of second-degree sinoatrial block and rare moments of sinus tachycardia. In addition, moments of premature multifocal ventricular extrasystoles and 1st-degree atrioventricular block were observed. Based on the Holter results, heart rate variability (HRV) was calculated. Regarding the HRV in the frequency domain, 32.16 was obtained in the low frequency (LF) band, 67.84 in the high frequency (HF) band, and the LF / HF ratio was 0.46, with a total power of 5205. As for the HRV in the time domain, RMSSD was 117, pNN50 was 62.64 and SDNN was 384. This showed an increase in the parasympathetic activity of the heart and, due to this increased activity, a second-degree sinoatrial block occurred, which is a sinus function disturbance resulting from the exacerbated parasympathetic activity.

Discussion: Beta-adrenergic receptors have their expression and activity altered by thyroid hormones. The sympathetic stimulation on the heart through the activation of these receptors originates a positive inotropic, lusitropic, dromotropic and chronotropic effect. Therefore, in the absence of thyroid hormones, there is a decrease in this stimulation, thus allowing a preponderant parasympathetic tone. In the present report, the increase in the parasympathetic tonus, observed in hypothyroidism, resulted in a reduction in the frequency of sinus firing, slowing of intranodal and sinoatrial conduction, and shortening of the effective refractory period, a combination of factors that led to decreased HR observed in the Holter monitoring. Previous studies have shown that thyroid hormones increase sympathetic activity, mainly in the heart, since they do not act by increasing the production or release of catecholamines, but rather increasing catecholamine response on the heart, due to a positive regulation of $\mathrm{Ca} 2+-\mathrm{ATPase}$ channels of the sarcoplasmic reticulum and beta1-adrenergic receptors. Thus, the observed result was already expected, because in hypothyroidism there is a decrease in these hormones that increase the sympathetic activity on the heart and so, the parasympathetic tone was very evident. The study of heart rate variability allows the simple assessment of the autonomic nervous system imbalance, and may be extremely important in the follow-up of diseases that affect this balance, such as hypothyroidism. Hence, more studies are required to verify the effect of such diseases on heart rate variability, aiming to define associations between the diseases and the alterations, as well as to define parameters of normality for such examinations.
\end{abstract}

Keywords: atrioventricular block, sinoatrial block, electrocardiography, heart rate variability.

${ }^{1}$ Programa de Pós-graduação em Farmacologia, Universidade Federal do Ceará (UFC), Fortaleza, CE, Brazil. ${ }^{2}$ Departamento de Medicina Veterinária (DMV), Universidade Estadual do Ceará (UECE), Fortaleza. ${ }^{3}$ MV. Autônomos, Fortaleza. CORRESPONDENCE: P.P.C. Costa [paulapriscilamv@ yahoo. com.br - Tel.: +55 (85) 996569812]. Departamento de Fisiologia e Farmacologia, Faculdade de Medicina, Universidade Federal do Ceará (UFC). Rua Coronel Nunes de Melo n.1127. Bairro Rodolfo Teófilo. CEP 60430-275 Fortaleza, CE, Brazil. 


\section{INTRODUCTION}

A 7-year-old female Dalmatian dog, weighing $36 \mathrm{~kg}$, was treated at Clínica Veterinária Bom pra Cachorro in the city of Fortaleza, state of Ceará, Brazil. During the anamnesis, the dog's owner reported that she had been apathetic for a year, had gained weight, always had a sad expression, and her hair was generally brittle and opaque. On physical examination, skin lesions were observed at the end of the spine, extending to the tail region, with the latter showing total alopecia. The temperature was normal. Mucous membranes were pink and the capillary refill time was less than $2 \mathrm{~s}$. The heart auscultation disclosed a 3/6 murmur in the mitral valve and 2/6 murmur in the tricuspid valve area and heart rate (HR) was between $40-50 \mathrm{bpm}$, that is, bradycardic but apparently regular HR.

Hormonal levels were measured: TSH $(0.65$ $\mathrm{ng} / \mathrm{mL})$ range $(0.04$ to $0.4 \mathrm{ng} / \mathrm{mL})$, free $\mathrm{T} 4(0.11 \mathrm{ng} /$ $\mathrm{mL})$ range $(0.6$ to $2.0 \mathrm{ng} / \mathrm{mL})$ and total $\mathrm{T} 4(0.44 \mathrm{ng} /$ $\mathrm{mL}$ ) range (1.2 to $4.0 \mathrm{ng} / \mathrm{mL})$.

After the diagnosis of Primary Hypothyroidism was confirmed, an ECG was performed, which showed a $1^{\text {st }}$-degree atrioventricular block (AVB) and bradyarrhythmia. Therefore, a 24-h Holter was performed, in which overall electrical disturbances and heart rate variability (HRV) were analyzed in the frequency and time domain.

To capture the cardiac electrical activity signs, adhesive electrodes were adhered to the skin surface, after the latter was adequately shaved. These electrodes were positioned between the $5^{\text {th }}$ and $6^{\text {th }}$ right (negative electrode) and left (positive electrode) intercostal spaces, at the junction between the upper and middle third of the thorax, forming the $\mathrm{X}$ axis; in the region of the manubrium (negative electrode) and xiphoid

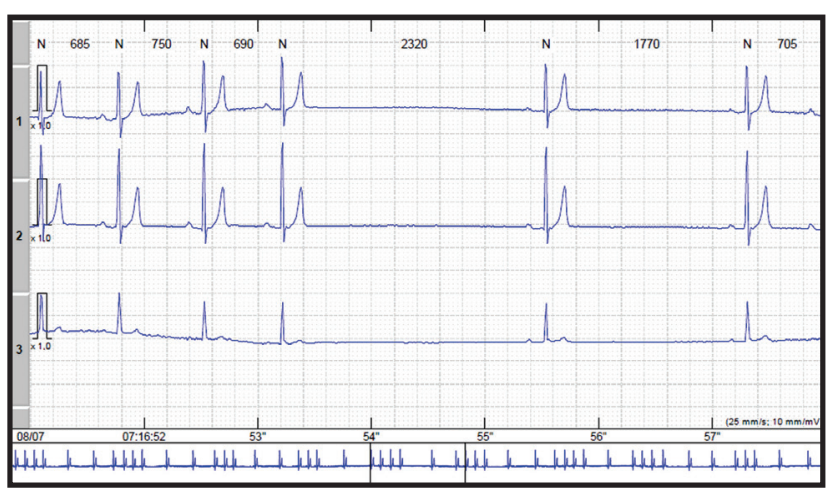

Figure 1. The 24-h Holter recorded 320 events of pauses lasting longer than $2.0 \mathrm{~s}$; this tracing illustrates the longest pause, which lasted $2.3 \mathrm{~s}$. cartilage (positive electrode), forming the $\mathrm{Y}$ axis; on the T7 spinal process (negative electrode) and on the opposite ventral aspect (positive electrode), forming the $\mathrm{Z}$ axis. To cover and protect the electrodes, bandages were applied to the dog's thorax, as well as in the three-channel digital recorder (Cardioflash digital) ${ }^{1}$. The 24-h electrocardiographic tracings were processed using a specific software (CardioMananger S540) ${ }^{1}$.

The 24-h Holter monitoring lasted 23 h 59 m. Heart rate (HR) ranged from $35 \mathrm{bpm}$ at $218 \mathrm{bpm}$, with a mean of $75 \mathrm{bpm}$. However, heart rate was below 50 $\mathrm{bpm}$ for 05:20:36 h and above $120 \mathrm{bpm}$ for 00:06:56 h. There were 320 events of HR pauses exceeding $2.0 \mathrm{~s}$. The longest pause lasted $2.3 \mathrm{~s}$ (Figure 1). The 1:1 A-V conduction with PR interval was predominantly within the normality parameters (ranging from 120 to $130 \mathrm{~ms}$ ), intercalated with $1^{\text {st }}$-degree AVB moments (PR interval ranging from 140 to $160 \mathrm{~ms}$ ), usually associated with HR $<85 \mathrm{bpm}$. Adequate QT intervals (ranging from 230 to $250 \mathrm{~ms}$ ). No occurrences of ST-segment depression or elevation were recorded. No supraventricular ectopies, 6 events of ventricular ectopies (Figure 2), 6 isolated ectopies, 0 paired ectopies and 0 tachycardias were recorded.

Overall, it was concluded that the animal had sinus arrhythmia associated with moments of $2^{\text {nd- }}$ -degree sinoatrial block (SAB) [Figure 3] and rare moments of sinus tachycardia, in addition to premature multifocal ventricular extrasystoles, moments of $1^{\text {st }}$-degree AVB, low-incidence electrical ventricular instability and moderate/ high incidence atrioventricular conduction disorders. Moreover, ventricular repolarization without criteria for the diagnosis of myocardial hypoxia was also observed.

For the heart rate variability (HRV) study, the standard deviation of all RR intervals (SDNN), the root mean square of successive $\mathrm{NN}$ interval differences

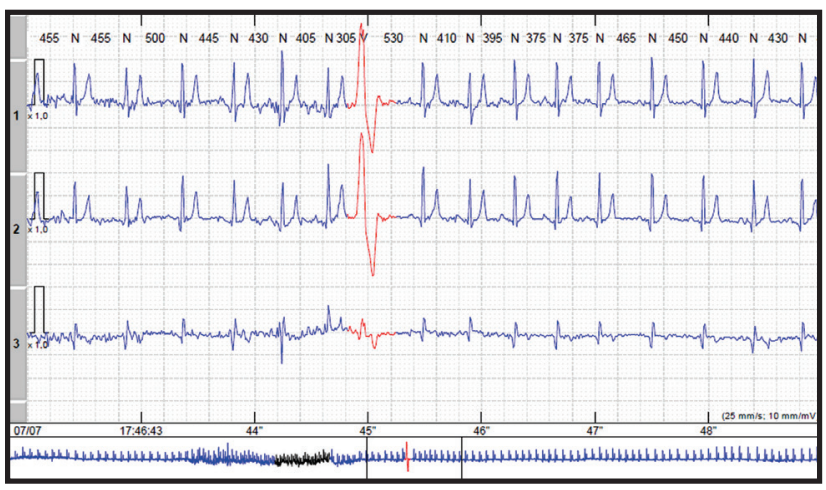

Figure 2. Isolated ventricular ectopy in red, as shown by the Holter monitoring. 


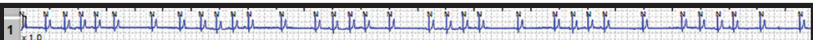

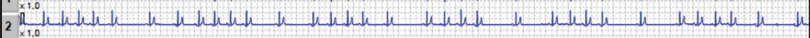

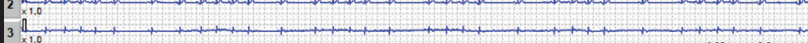

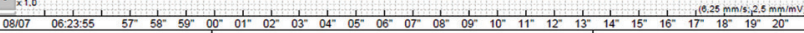

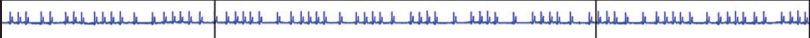

Figure 3. Electrocardiographic recording showing sinus arrhythmia with $2^{\text {nd }}$-degree sinoatrial block.

between adjacent RR intervals (rMSSD) and the percentage of adjacent RR intervals with duration difference $>50 \mathrm{~ms}$ (pNN50) were assessed, whereas in the frequency domain the wave components were divided into high frequency $(0.15$ to $0.4 \mathrm{~Hz}$ ), low frequency $(0.04 \mathrm{~Hz}$ to $0,15 \mathrm{~Hz})$, in addition to the quantification of the total power and the LF/HF ratio, based on the electrocardiographic recording documented in $24 \mathrm{~h}$ of examination at each moment of evaluation.

Regarding the HRV in the frequency domain, 32.16 was obtained in the low frequency (LF) band, 67.84 in the high frequency (HF) band, and the LF/HF ratio was 0.46 , with a total power of 5205 . As for the HRV in the time domain, RMSSD was 117, pNN50 was 62.64 and SDNN was 384 .

\section{DISCUSSION}

Hypothyroidism confirmatory tests comprise hormonal measurements. The results obtained from the patient in this report were TSH elevation and decreased free T4 and total T4. Approximately $90 \%$ of dogs with hypothyroidism have decreased total T4 and increased TSH concentration by 65 to $75 \%$; therefore, it is an important marker for the identification of primary hypothyroidism [11].

The myocardium is the tissue that contains the most receptors for thyroid hormones, which affects the generation frequency, as well as the duration of cardiomyocyte action potential through genomic and non-genomic mechanisms. Additionally, changes in thyroid hormone levels may affect the gene expression of cardiomyocytes and, consequently, induce changes in cardiac function $[9,15]$.

Thyroid hormones act on cardiomyocytes, resulting in an increase in beta-adrenergic receptor expression [20], increasing the expression of $\mathrm{Ca}^{2+-}$ -ATPase present in the sarcoplasmic reticulum, as well as decreasing the expression of phospholamban, which is a regulatory protein that inhibits $\mathrm{Ca}_{2}{ }^{+}$-ATPase activity [3]. However, in addition to the thyroid influence, the cardiovascular system is under the constant influence of the autonomic nervous system (ANS) [14].
Beta-adrenergic receptors have their expression and activity altered by thyroid hormones. The sympathetic stimulation on the heart through the activation of these receptors originates a positive inotropic, lusitropic, dromotropic and chronotropic effect [1]. Therefore, in the absence of thyroid hormones, there is a decrease in this stimulation, thus allowing a preponderant parasympathetic tone.

In the present report, the increase in the parasympathetic tonus, observed in hypothyroidism, resulted in a reduction in the frequency of sinus firing, slowing of intranodal and sinoatrial conduction, and shortening of the effective refractory period, a combination of factors that led to decreased HR observed in the Holter monitoring. Secondary SAB is a sinus function disorder resulting from an overly abnormal parasympathetic tone [4] due to the activation of M2 receptors that reduce cardiac contraction force and heart rate frequency, which is associated with the inhibition of voltage-dependent $\mathrm{Ca} 2^{+}$channels and the activation of $\mathrm{K}+$ rectifier channels through $\mathrm{Gi} / \mathrm{o}$ stimulation [2]. Therefore, AVB disorders are derived from the increase in the refractory period caused by the inhibition of ICa-L, also caused by the increase in the parasympathetic tone.

Ventricular ectopies, although sporadic in the examination, should be monitored. In a study that evaluated 50 dogs through 24-h Holter monitoring, the authors concluded that ventricular ectopies are rare in healthy adult dogs, and that the presence of a high and sequential number of them may suggest cardiac or systemic disease [8].

Heart rate variability is a simple and non-invasive method of quantitatively assessing autonomic heart modulation and the risk of cardiovascular disorders in different types of patients [18].

There is some difficulty in finding parameters of normality for $\mathrm{HRV}$ in dogs; therefore, the parameters used in this study were based on a dissertation that assessed heart rate variability in obese and normal weight animals, as compared to values found in the present article. In the abovementioned study, the values found in normal dogs were: total power (7434.65), LF/ $\mathrm{HF}$ (2.72), rMSSD (78.55), pNN50 (33.31) and SDNN (182.32) [7].

HRV analysis in the frequency domain showed an increase in the high frequency band, an indicator of vagal activity, in parallel with a decrease in the low 
frequency band, due to the joint sympathetic and parasympathetic activities [6], but with a predominance of the sympathetic system. Therefore, there was a decrease in the LF/HF ratio, indicating an increase in the parasympathetic system. The low HRV, represented by Total power, is frequently an indicator of abnormal and insufficient adaptation of the ANS, which may indicate the presence of physiological malfunction in humans, requiring further studies to attain a specific diagnosis [13].

Regarding heart rate variability in the time domain, the rMSSD and pNN50 indices are indicators of parasympathetic activity on the heart $[10,16]$, and SDNN can indicate heart variability $[12,17]$. The result of HRV in the time domain confirms what was observed in the frequency domain, that is, an increase in the rMSSD, pNN50, was identified, confirming there was an increase in the parasympathetic activity on the heart. However, the opposite was observed in relation to SDNN, showing an increase in this parameter, indicating an increase in HRV.

Previous studies have shown that thyroid hormones increase sympathetic activity, mainly in the heart, since they do not act by increasing the production or release of catecholamines, but rather increasing catecholamine response on the heart, due to a positive regulation of $\mathrm{Ca}^{+}$-ATPase channels of the sarcoplasmic reticulum and beta1-adrenergic receptors [3]. Thus, the observed result was already expected, because in hypothyroidism there is a decrease in these hormones that increase the sympathetic activity on the heart and so, the parasympathetic tone was very evident.

However, a decrease in cardiac variability was observed, if one considers the total power, and a high heart variability is associated with a good adaptation, characterizing individuals with an efficient autonomic nervous system, whereas a low heart variability is related to a low or inefficient adaptation, being a predictive factor of mortality in humans with acute myocardial infarction [5,19].

According to the present report, there was an increase in the parasympathetic tonus and electrophysiological disorders, as expected for a patient with hypothyroidism. However, more studies on dogs are required on the subject.

\section{CONCLUSION}

The HRV study allows a simple and effective evaluation of the autonomic activity imbalance. In this report, the analysis of electrocardiographic aspects during $24 \mathrm{~h}$ and the HRV showed the presence of parasympathetic dysfunction in a dog with hypothyroidism. This report ratifies a greater need for further research in this field.

\section{MANUFACTURER}

${ }^{1}$ Cardio Sistemas Comercial e Industrial Ltda. Paraíso, SP, Brazil.

Declaration of interest. The authors report no conflicts of interest. The authors alone are responsible for the content and writing of the paper.

\section{REFERENCES}

1 Bers D.M. 2002. Excitation-contraction coupling and cardiac contractile force. 2nd edn. Dordrecht: Kluwer Academic Publishers, 429p.

2 Caulfield M.P. 1993. Muscarinic receptors-characterization, coupling and function. Pharmacology \& Therapeutics. 58: 319-379.

3 Danzi S. \& Klein I. 2014. Thyroid disease and the cardiovascular system. Endocrinology Metabolism Clinics of North America. 43: 517-528.

4 Kaul U. \& Grigg L. 1985. Cardiac pacing in sino-atrial bradyarrhythmias. Reblampa. 8(3): 254-264.

5 La Rovere M.T., Bigger J.T., Marcus F.I., Mortara A. \& Schwartz P.J. 1998. Baroreflex sensitivity and heart-rate variability in prediction of total cardiac mortality after myocardial infarction. Lancet. 35: 478-484.

6 Lopes P.F.F., Oliveira M.I.B. \& Max S. 2013. Aplicabilidade Clínica da Variabilidade da Frequência Cardíaca. Revista Neurociências. 21: 600-603.

7 Mazini A.M. 2011. Avaliação da ocorrência de arritmias e da variabilidade da frequência cardíaca em cães obesos pelo método Holter. 144f. São Paulo, SP. Dissertação (Mestrado) - Dissertação apresentada ao Programa de Pós-graduação em Clínica Veterinária e Zootecnia da Universidade de São Paulo.

8 Meurs K.M., Spier A.W., Wright N.A. \& Hamlin R.L. 2001. Use of ambulatory electrocardiography for detection of ventricular premature complexes in healthy dogs. Journal of the American Veterinary Medical Association. 218: 1291-1292. 
9 Morkin E. 1993. Regulation of myosin heavy chain genes in the heart. Circulation. 87: 1451-1460.

10 Oliveira M.S., Muzzi R.A., Araujo R.B., Muzzi L.A., Ferreira D.F., Nogueira R. \& Silva E.F. 2012. Heart rate variability parameters of myxomatous mitral valve disease in dogs with and without heart failure obtained using 24hour Holter electrocardiography. Veterinary Record. 170: 622.

11 Panciera D.L. \& Caar AP. 2007. Endocrinologia para o Clínico de Pequenos Animais. São Paulo: Roca, 200p.

12 Piccirillo G., Ogawa M., Song J., Chong V.J., Joung B., Han S., Magri D., Chen L.S., Lin S.F. \& Chen P.S. 2009. Power spectral analysis of heart rate variability and autonomic nervous system activity measured directly in healthy dogs and dogs with tachycardia-induced heart failure. Heart Rhythm. 6: 546-552.

13 Pumprla J., Howorka K., Groves D., Chester M. \& Nolan J. 2002. Functional assessment of heart rate variability: physiological basis and practical applications. International Journal of Cardiology. 84: 1-14.

14 Reis A.F.D., Bastos B.G., Mesquita E.T., Romêo F., Martins L.J. \& Nóbrega A.C.L.D. 1998. Disfunção parassimpática, variabilidade da frequiência cardíaca e estimulação colinérgica após infarto agudo do miocárdico. Arquivos Brasileiros de Cardiologia. 70: 193-99.

15 Sun Z.Q., Ojamaa K., Coetzee W.A., Artman M. \& Klein I. 2000. Effects of thyroid hormone on action potential and repolarizing currents in rat ventricular myocytes. American Journal of Physiology-Endocrinology and Metabolism. 278: 302-307.

16 Stein K.M., Borer J.S., Hochreiter C., Okin P.M., Herrold E.M., Devereux R.B. \& Kligfield P. 1993. Prognostic value and physiological correlates of heart rate variability in chronic severe mitral regurgitation. Circulation. 88: 127135 .

17 Task Force of the European Society of Cardiology. 1996. Heart rate variability standards of measurement, physiological interpretation, and clinical use. European Heart Journal. 17: 354-381.

18 Thuraisingham R.A. 2006. Preprocessing RR interval time series for heart rate variability analysis and estimates of standard deviation of RR intervals. Computer Methods and Programs in Biomedicine. 83: 78-82.

19 Vanderlei L.C.M., Pastre C.M., Hoshi R.A., Carvalho T.D.D. \& Godoy M.F.D. 2009. Noções básicas de variabilidade da frequência cardíaca e sua aplicabilidade clínica. Revista Brasileira de Cirurgia Cardiovascular. 24: 205-217.

20 Williams L.T., Lefkowitz R.J., Watanabe A.M., Hathaway D.R. \& Besch H.R. 1977. Thyroid hormone regulation of beta-adrenergic receptor number. Journal of Biological Chemistry. 252: 2787-2789. 